\title{
REVIEW OF VEHICLE TELEMATICS USAGE BASED INSURANCE - CONTRIBUTION TO SUSTAINABLE INSURANCE STRATEGY
}

\author{
Aleksandar Nedić* \\ Dunav Insurance Company, Belgrade, Serbia \\ Nemanja Nedić \\ Singidunum University, Belgrade, Serbia \\ Igor Stevanović \\ Porshe Belgrade North, Belgrade, Serbia \\ Darko Stanojević \\ Faculty of Mechanical Engineering, Belgrade, Serbia
}

The purpose of insurance is to provide security for the clients and its partners, by perfectly and responsibly understand, manage, monitor and carry the risk. As a powerful motor of global industry, insurance also have a potential to contribute enhancement of society, economy and governance, with strong positive influence on the environment. Sustainable insurance is a strong commitment of the insurance sector to recognize the sustainable values and determination to integrate these values in their strategy. In the new way of looking to the future, principals of insurance sector are in the best position to initiate and to assist in resolving complex global challenges-climate change issues and impoverishment of natural resources. In this paper will be discussed about the auto Telematics Usage Based Insurance products. These products are promoted by the insurance sector in accordance with natural progress of society and legal framework, evolution of technology and changes in demands. They can be classified as perspective solutions for sustainable insurance, because they directly affect environmental, safety, energy and resources saving, and overall social improvement issues.

Key words: Sustainable insurance, Risk, Environment, Climate Change, Usage based insurance, Vehicle telematics

\section{INTRODUCTION}

The highest values of sustainable concept, and its application in operational management of large financial companies, are aggregated and promoted by the UNEP FI, and by the IWG, as separate part of it, through UNEP, indicating the benefits which can be made through responsible way of investing, with purpose of fighting against climate change. Risks arising from climate changes already have the greatest consequences to insurers, since they have to change the business environment, aiming improvement of their operations and financial performance. [01]

Encouraged to act proactively, insurance sector can make further progress in environmental, social and governance issues, through development of new products and added-value services for its clients. Striving to widespread right policy measures, mitigation of risks which can be associated with the implementation of sustainable and green technologies, making insurance underwriting and rate calculation process more adjusted to individuals, promote ecological and safe driving behavior, prevention and control of loss, insurance sector revolutionary change trends.

With about a billion vehicles worldwide, road transportation has a strong influence on world's economy and society. It generates a large part of all manmade greenhouse gases, and millions of people died and got seriously injured, as a part of it, globally, per year. [12] These reasons were the main motive for several campaigns which, over the past two decades, had been constantly changing the expression of legislation and created innovative insurance solutions. 


\section{USAGE BASED INSURANCE PROGRAM}

Usage based insurance program defines a customized premium rate determined by the data collected from the insured vehicle. To this purpose a telemetric device must be installed on the vehicle, after acceptation of consumer, so the insurance company can carry out realtime monitoring on how insured vehicle is used. Idea of paying insurance in relation to the usage (flown distance-miles/kilometers-distance based insurance) of the vehicle came over 50 years ago, when fixed-price system had been criticized, as being inefficient and unfair to the consumers. Coinciding with initiatives to raise awareness about the issues of road transportation, considering safety and air emission, after several method of Distance Based Insurance, new „Pay As You Drive“ premium models were endorsed and brought to light from the studies in Europe and USA. These new usage models, satisfying the growing demands, for the first time were depending on road usage category, time usage and age usage differentiation [05].

Combination of standard-traditional risk rating and underwriting factors such as: driving and credit record, history of claims, vehicle type and model, address, marital status, having a garage or not (etc. depending on Insurer's quote), with singularity of usage, resulted as unique premium formula for consumer of insurance. This change of pricing method had to be done, because it brought higher quality in relationship between insurance and consumers, created more fair ambient with different options, added other valuable services, and revealed a great potential to reduce negative effects of vehicle usage. Uncompromising development of informatics and telecommunication technologies, allowed further progress in the field of usage based auto insurance products innovation - telematics insurance. Figure 1 provides a graphic representation of Telematics UBI programs evolved over time (Telematics Timeline) [04].

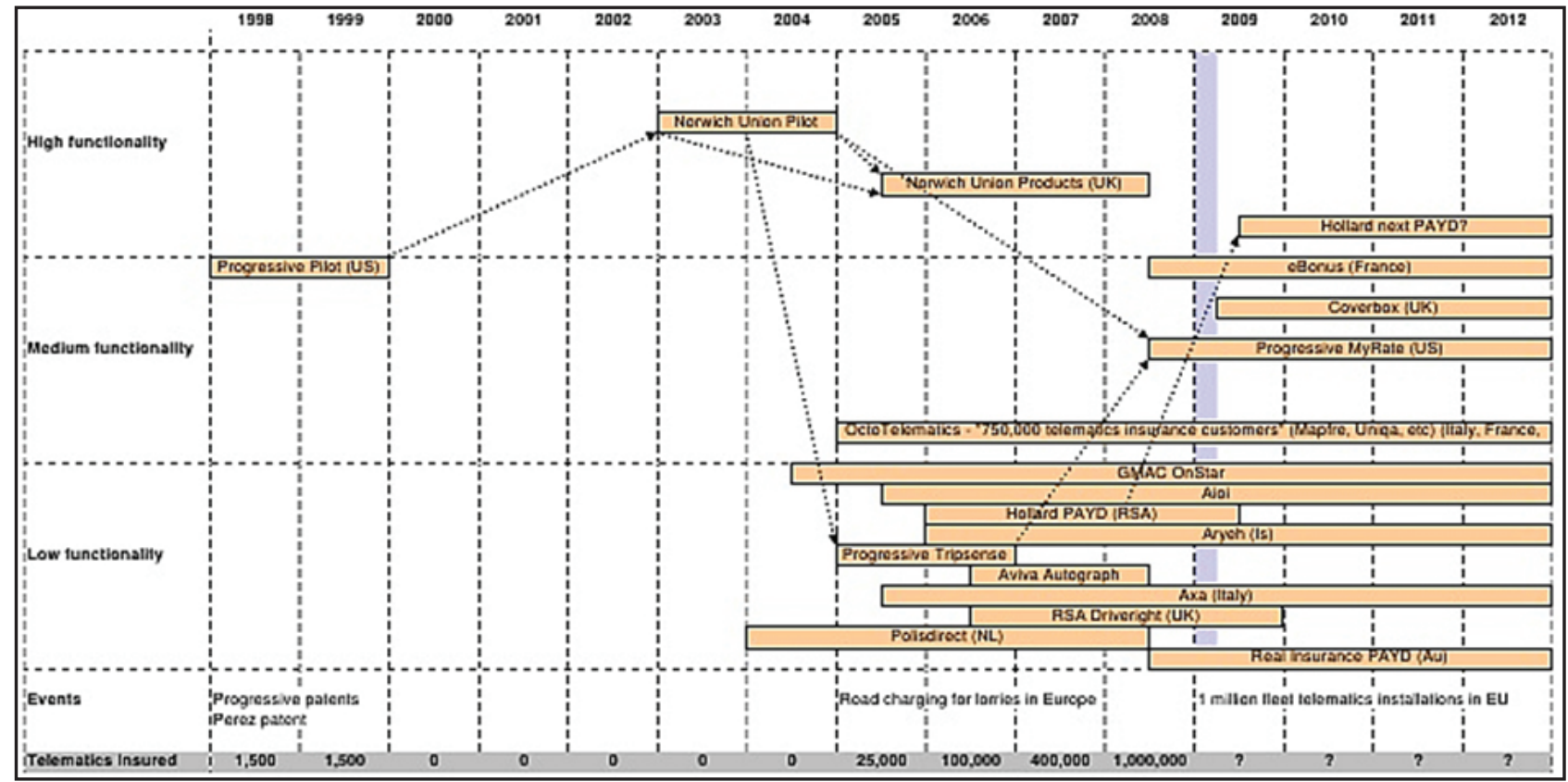

Figure 1: Telematics Timeline

\section{USAGE BASED INSURANCE AND TELEMATICS}

Comparing these two concepts, one must underline that the Usage Based Insurance is broader term comprising different types of methodology to take over data from the vehicle, according to different implemented technology. Former method of collecting data implied a device called odometer, which contains information of total distance driven, and had to be reported to the insurer, so premium can be calculated. The real revolutionary concept that changed trends of auto insurance sector, is premium calculating model based on wireless, real-time data transmission through telematics device, from the vehicle to insurance company. This compound of information and technology enabled further creation of two similar, and nowadays, most common products - Pay As You Drive and Pay How You Drive. 
Telematics PAYD is GPS based pricing scheme, with installed device that tracks driven distance-number of miles/kilometers, for which consumer has to pay fixed amount of premium per each driven unit. That means, there is no obligation of payment if consumer doesn't drive, but also means if consumer drives then, besides the distance driven, insurance also tracks when is a vehicle driven (time of day and night, working day or weekend) and what kind of route was chosen for the trip (urban area or highway, for example). This implication gives choice and some control to the policyholder over how much he will pay for insurance, which is good from the aspect of fairness.
Telematics PHYD is also GPS based pricing scheme, but more sophisticated, with gyroscope and accelerometer integrated in addition, for sensing direction and motion. Purpose of device is to track even greater number of information about the vehicle, besides the distance driven, such as: location, time, date, speed, acceleration, braking, even the way of lane changing, on the basis of which is possible to understand the behavior of the driver, and according to the profile, assign the right rate and to form premium price (different price per driven unit). On the Figure 2, it is shown how it operationally works, according to Progressive Insurance Corporation. [08]

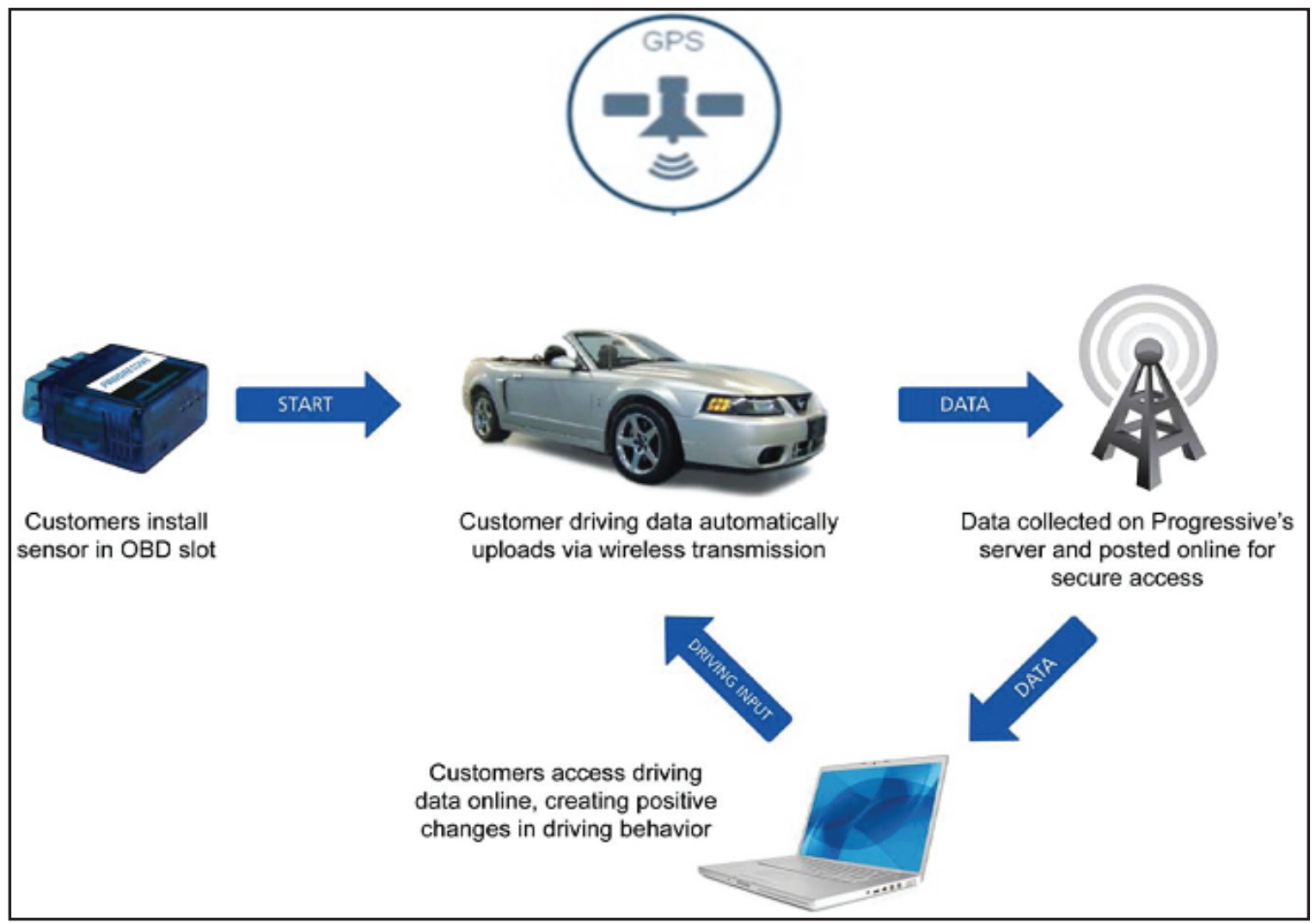

Figure 2: Schematic operational view of telematics insurance, by Progressive In. Corp.

Telematics Insurance has become a mainstream, judging by not just Insurers but also policyholders acceptance, as well as global public awareness, with forecast of estimated premium value over $€ 50$ billion in Europe and over $\$ 30$ billion in US, by 2020., experts predict. [10] On Figure 3 it is shown a market-share of the usage based policies, enabled by using telematics devices, in EU and US, and predicted trend to the end of decade. According to the source, Italy is the country with the greatest and the fastest market penetration of telematics insurance products, even beyond the borders of EU.

\section{DATA USE AND MANAGEMENT}

For a quality classification of drivers, based on analyzed driving behavior, there is a need of large amount of complex data. All of collected data, insurance or the third party must put in order, so this data can become useful information for realization of pricing plan. Depending on adopted strategy and multitude of factors, different plans, applications and tools are needed. 


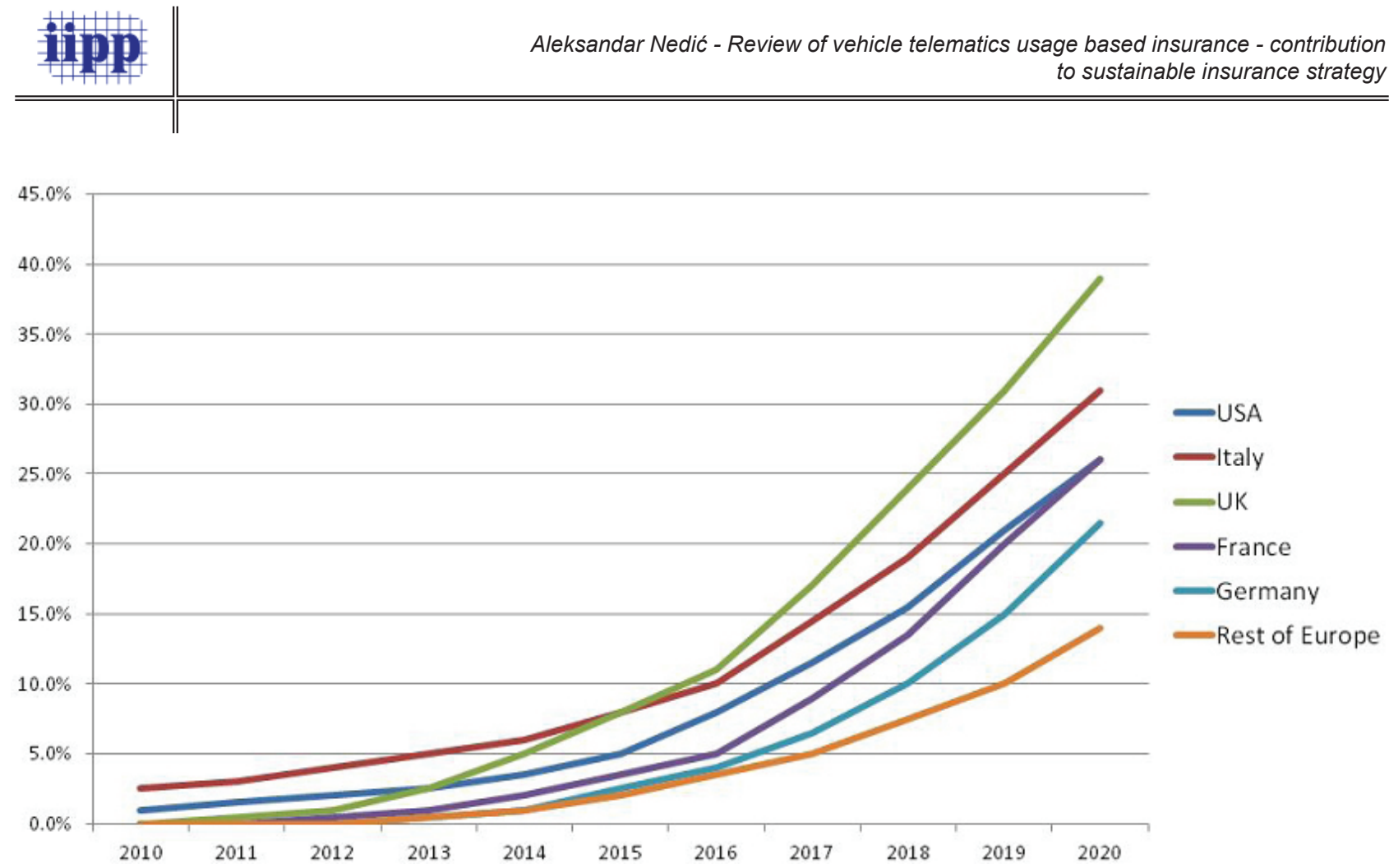

Figure 3: Market Share of Telematics UBI, source: Ptolemus, Global Insurance Telematic

Level of technology development and its independent breakthrough on various markets worldwide, likewise affect utilization of different equipment for affirmation of usage based insurance products. Four different technologies carries out the usage based concept, such as: embedded OBUs, OBDs, black boxes and smart phones.

Because of incredible size (terabytes per year) and sophistication of data generated from drivers/vehicles, which will become a material for further actuarial process, there is always a question for insurer, what is the best possible solution for handling this valuable material, from the aspect of process cost and privacy of policyholder. In growing number of cases, third party manage collecting, processing and rating for Insurer, and sometimes, Insurer and third party divide preparation of data. At the end, prepared data is shaped into rates with actuarial methodology. Outsourcing in this occasion can be "two-edged sword“, because consumers are very suspicious about possible invasion of privacy. Second problem is migration of data, in possible scenario of changing insurer by the driver/vehicle on demand, and transferring to a different system without existing unified data standard. A lot more have to be done in a field of data usage and management, with profitability of the process set on a last place of expectations.

Another significant value of data collection was the opportunity for Insurers and Researchers to find relation between the distance driven, risk and claims. Strong relations were found in several studies such as Bordof and Noel [02], with database of pioneer telematics-based policies Insurer - Progressive Insurance Corporation, and Ferreira and Minike. [03] Reduction on crashes on a global scale is very much desired goal and it is already achieved, after the application of UBI products. [10] This is particularly valuable for target group of young drivers, between age of 18 and 30 , which carries the largest share of accidents number.[11]

\section{BENEFITS AND CONCERNS OF TELEMATICS USAGE-BASED-INSURANCE}

- Benefits from adopting Usage Based Insurance for the policyholder are:

- Increased accuracy of pricing;

- Lower price of insurance for $10 \%-50 \%$ in overall:

- By getting a discount in adopting UBI solution,

- By being stimulated for safe driving, better driving behavior and less usage

- Improvement in safety with adjustment of driving habits through active feedback;

- Lower fuel consumption, lower maintenance costs;

- Value added services:

- E-Call services, stolen vehicle tracking, on-board diagnostic, vehicle healthy reports, customer-friendly services 
Benefits for insurers are:

- Customized pricing method, oriented and adjusted to the client;

- Improving customer's driving behavior;

- Reduction of accidents frequency and negative loss ratio, accordingly higher profit;

- Reduction of fraud;

- Reduction of operational costs;

- Achieve consistency in the implementation of sustainable development strategy (reduction of $\mathrm{CO} 2$, etc.)

\section{CONCERNS}

Policyholders have a major concern over:

- Possible increase of premium price

- Possible violation of privacy - concern that specific collected data can be shared with others.

\section{CONCLUSION}

There are over a billion vehicles on the roads around the globe. With innovative insurance products, such as Telematics Usage Based, Insurers have the opportunity to promote the values of sustainable development and reduce negative impact of road transportation to the environment. Studies had shown that economic style of driving have various benefits - less fuel consumption, less made greenhouse gases, and less accidents. Drivers with adequate driving behavior are preferred as policyholders and favorable for the environment. With constant promotion of safety and behavior modification programs, as well as providing resources aiming compensation for casualties, insurance sector strongly support sustainable development and must be consistent in determination to find new solutions and constantly improves services.

\section{REFERENCES}

1) Bordoff, Jason E., Noel, Pascal J. (2008): Pay-As-You-Drive Auto Insurance: A Simple Way to Reduce Driving-Related Harms and Increase Equity, The Brookings Institution (www.brookings.edu); at www.brookings.edu/papers/2008/07_payd_bordoffnoel. aspx.

2) Ferreira, Joseph Jr., Minike, E. (2010): PayAs-You-Drive Auto Insurance In Massachusetts: A Risk Assessment And Report On Consumer, Industry And Environmental Benefits, by the Department of Urban
3) http://www.slideshare.net/emilyjsavage/insurance-telematics-by-robin-harbage-ofemb

4) Litman,T.(2011): Distance-Based Vehicle Insurance, Feasibility, Costs and Benefits - comprehensive technical report, can be viewed at http://www.vtpi.org/dbvi_com.pdf

5) Mai,A. , Schlesinger, D. (2011): Connected Vehicle Insurance -The business of preventing crashes

6) Pavić, N., Popović, V., Vasić M. (2011): Drivers age as the dominant demographic factor in traffic accidents, Journal of Applied Engineering Science (Istraživanja i projektovanja za provredu), Vol. 9, No. 3, pp. 411-416

7) Progressive Insurance Corporation, US (2010): NAIC risk classification meeting presentation ( PIC launched the first telematics insurance product in 1998)

8) Ptolemus Consalting Group (2012): Global Insurance Telematic Study

9) Ptolemus Consalting Group, http://www.ptolemus.com/

10) Studies and Planning, Massachusetts Institute of Technology (http://dusp.mit.edu) for the Conservation Law Foundation (www.clf. org); at www.clf.org/our-work/healthy-communities/modernizingtransportation/pay-asyou-drive-auto-insurance-payd

11) UNEP FI (2007): Insuring for Sustainability - Why and how the leaders are doing it - The inaugural report of the Insurance Working Group of the United Nations Environment Programme Finance Initiative, can be viewed at http://www.unepfi.org/fileadmin/ documents/insuring_for_sustainability.pdf

12) Vujović, R. (2009): Uticaj globalizacije i klimatskih promena na stanje rizika i troškova osiguranja, Journal of Applies Engineering Science ( Istraživanja i projektovanja za privredu), Vol. 8, No. 23-24, pp. 41-55

Paper sent to revision: 11.03.2014.

Paper ready for publication: 04.06.2014. 